\title{
Electrical Engineering Teaching and Distance Learning using a Desktop Virtual Reality System
}

\author{
M. Travassos Valdez \\ Instituto Superior de Engenharia \\ de Coimbra (IPC/ISEC) \\ Coimbra, Portugal \\ valdez@isec.pt
}

\author{
C. Machado Ferreira \\ Instituto Superior de Engenharia \\ (IPC/ISEC) and INESC Coimbra \\ Coimbra, Portugal \\ cmacfer@isec.pt
}

\author{
F. P. Maciel Barbosa \\ Faculdade de Engenharia \\ Universidade do Porto \\ and INESC TEC Porto, Portugal \\ fmb@fe.up.pt
}

\begin{abstract}
Higher education has evolved in the last decade with the use of information technology. This change was called distance education, a teaching method in which the student does not need to meet with the teacher on a certain day and time. The student may be either at home or at work and may have no interaction with the other parts, either the teacher or other students. It has allowed the institutions to resolve geographical gaps in order to reach the largest number of students. On the other hand, it paved the way for the "non-traditional" universities oriented for "adult work", in a narrow range of graduation programs, compatible with the current demands from industry. It is also important to mention that distance education is becoming increasingly appropriate for nonacademic studies, such as corporate training environments.

This paper addresses Circuit Theory systems, more specifically laboratory practices geared towards teaching and learning. The choice was made from observing the needs in the specific context of a measures and instrumentation laboratory, mainly related with access to the means and equipment to carry out laboratory practice. The purpose of the work is the use of virtual experimentation to carry out laboratory practice and also as an alternative tool to meet the needs of access to the means and equipment of the laboratory.

In the present case, the basis of the project was the construction of a 3D lab environment (Measures and Instrumentation) where the equipment and the components can be seen and manipulated. The project involves simple electrical schematics, which later can be changed in values, presenting new results, and displays a set of menus and submenus to support experiments. The virtual laboratory can accommodate new devices and scenarios, being adapted to new subjects, such as electric machines and power system analysis of the Electrical Engineering program.

This work was developed to demonstrate how a desktop VR prototype, "Virtual Electric Manual" - VEMA, can be applied to an engineering unit and used to enhance security and resourcefulness in using electrical equipment. Several interactive scenes were developed to illustrate the idea using a measurements and instrumentation laboratory as virtual environment.

The added value of these various features in the educational context is that they contribute to the construction of new virtual environments, able to benefit the communication between teachers and students and among themselves, thus creating new opportunities for each student to participate more actively in his/her own learning construction process. Rather than being seen as mere information files, these e-learning platforms should be perceived as a means to promote interaction and experimentation through technological resources.
\end{abstract}

Index Terms-- Electrical Engineering, Teaching and Distance Learning, Virtual Reality System

\section{INTRODUTION}

In recent years approaches that integrate teaching and learning technologies in complex engineering applications have been presenting the concepts used and the creation of educational contents in a very appealing way [1-3]. The process of education in electrical engineering means the learning of theory and practice, the existence of self-study, team projects, experimental work involving equipment, packages of software simulation and laboratory applications. For the development of e-learning platforms for higher education in engineering, new methodologies should be taken into account with new methodologies of distance learning [4-7].

Each educational theory relates to a specific pedagogy used. The pedagogy proposed in this work used learning through discovery. The pedagogical approach is to provide a suitable environment for students, individually or not, to be challenged and stimulated to participate in experiments that will bring them closer to the desired goals. The knowledge of objects and equipment is organized to provide sufficient input for students to be able to reach a desired conclusion when exploring the learning environment.

The use of a constructivist pedagogy can consist in organizing laboratories as learning material and features such as an encyclopaedia or a catalogue which allow students to select the topic that they want to learn [8]. A constructivist laboratory can offer the opportunity for students to learn through interaction with familiar concepts and objects.

The new technology allows the laboratory environments to be transferred to a virtual environment using 3D computer models for educational purposes. However, 3D environments alone are not sufficient if there is no concern about the learning context [9-13]. This work discusses the relationship between styles and design of 3D laboratory environments based on pedagogical approaches.

In electrical engineering education the main problem is the explanation of procedures to be used in solving problems. This explanation may be based on the use of theoretical procedures using different methodologies. If the student has any questions, the difficulty lies in the way to answer them adequately. The lack of interactivity is a limitation, hindering the learning process and increasing the teacher's work, who has to create several types of examples. 
This problem is highlighted in the new plans of study of higher education (Bologna paradigm), in which the students' autonomous work increases significantly and the time of the teacher in the classroom is becoming more and more reduced.

Although the use of a virtual classroom may establish new channels of communication between the teacher and the student, in the case of electrical engineering, solving problems is still complicated. 3D web presentations are used as an alternative to settle matters [14].

Interactive $3 \mathrm{D}$ presentations are designed to facilitate the visualization, the understanding and resolution of electrical engineering problems. They can facilitate the understanding of the most important procedures for students of engineering [15-18]. The interactively moved three-dimensional models allow the modification and differentiation of the behaviour of objects. It is expected that the results obtained with this project will be very useful in electrical engineering as well as in other University/Polytechnic curricula requiring the visualization of three-dimensional problems.

With the use of the 3D web presentations, the various electric elements involved in an electrical installation can be easily understood by students. They can see the interaction between the equipment in various situations [12], [15].

\section{INTERACTIVE 3D PRESENTATIONS}

The main purpose of this project was to create interactive 3D presentations to facilitate the visualization, understanding and solving of engineering problems. This goal was divided into two parts:

- Creation of 3D models;

- Implementation of the interactive features of the 3D web presentations for an adequate handling.

Learning in online activities on sites requires a set of structured instructional principles to design learning materials. Several things are necessary: to know the target audience; there must be instructional objectives and clear strategies; the context for the learning process must be known; there must be examples and help on how to use the application; there must be contribution of interactive practical tasks in the learning process; and it must provide feedback on the learning activities [19].

Virtual reality is one of the most advanced technologies in the creation of forms of simulation. The simulation can be effectively carried out through the virtual reality environment. Users can interact with a simulated three-dimensional environment through computer-generated models.

\section{DISTANCE LEARNING}

Distance learning is a teaching method in which the student does not need to meet with the teacher on a certain day and time. The student may be either at home or at work and may have no interaction with the other parts, either the teacher or other students. It has allowed the institutions to resolve geographical gaps in order to reach the largest number of students [20-21]. On the other hand, it paved the way for the "non-traditional" universities oriented for "adult work", in a narrow range of graduation programs, compatible with the current demands from industry. It is also important to mention that distance education is becoming increasingly appropriate for non-academic studies, such as corporate training environments.

This form of learning, which optimizes time and space, is known as distance learning and it is being amply used in many different areas. Distance education presents the advantage of facilitating the teaching and learning processes without face-to-face interaction as knowledge is transmitted, partly or as a whole using technology. In fact, technological innovation has assumed a vital role in education. Looking to achieve more efficiency in carrying out the various activities, the job market constantly requires an investment in new skills and knowledge so that the professionals can operate the equipment and working tools, successfully and with quality.

Teaching is the planned response to the demands of the natural learning process in order to obtain optimal results; the teaching process must respect, facilitate and enhance the natural learning process. Learning requires continuity and a logical sequence as it is more than simple transmission of information; it requires methods, techniques, procedures and instruments to obtain satisfactory results. Each student is responsible for his/her own learning, and the teacher is just a facilitator and advisor. It is important to respect the students' different characteristics and their learning process should be accomplished in a more individualized manner.

Distance education (DE) is a teaching mode used to increase access to knowledge, being applied on a large scale in the continuing education of students and professionals. Its main feature is the physical separation between teacher and student. It has the potential to allow users with access to the internet to have information, courses and training in general at their disposal, at any moment.

Another advantage is the flexibility of time, which helps students who can't attend regular courses to keep updated in the labour market by means of structured material, without the need for face-to-face classes.

\section{3D WEB TECHNOLOGIES}

The use of three-dimensional virtual environments on the web has become more popular in recent years, not only in the form of games, but also as environments that simulate some aspects in real life [12], [15].

Virtual reality is quite effective for presenting information in virtual environments. It allows the reinforcement of the experiment as an informative resource with interactivity in a learning process through a 3D simulation.

Virtual reality is an interactive simulation of a sensory $3 \mathrm{D}$ environment that gives the illusion of a computergenerated experiment and visualization of virtual objects with spatial presence. Virtual reality can arise from programming 
environments such as Java3D, through coding environments such as Virtual Reality Modelling Language (VRML).

VRML is a language and a file format that allows to describe the movement, animations and interactive virtual environments. It was established as a standard for the creation of web-based contents in a $3 \mathrm{D}$ virtual form on the internet. The development of these standards allowed threedimensional worlds to be navigable online and in real time, opening a new set of possible applications for virtual spaces.

The realistic effects of design of a $3 \mathrm{D}$ virtual environment using the VRML can be combined with the HTML structure. The objects can be programmed with specific behaviors. Users are able to navigate with these same objects in a virtual world, with very realistic effects.

VRML allows the use of less powerful computers to display the dynamic 3D contents with high-quality visual information. However, it is not easy to learn and its syntax is not as flexible or intuitive.

\section{CASE STUDY - VEMA (VIRTUAL ELECTRICAL MANUAL)}

The overall idea was to create a three-dimensional model (3DS Max, Maya, Cinema 4 D, SketchUp, Blender, LightWave or any other 3D tool), reduce the size of the 3D objects with VizUp and then export them to WireFusion, where it was possible to add some interactivity. However, all animations had to be previously built in the source program of the 3D model. The last step was the production of interactive contents using HTML5, CSS3 and Javascript and the introduction of the presentations on the web as offline presentations [22-24].

In the design of a virtual reality system, the selection of the most appropriate tool is an essential component in the development of a VR program. The level of flexibility and pre-programmed components can vary substantially among software tools. Many resources require a special attention from the designers regarding the supported file formats for 3D importing models, polygon count, object sizing, type of animation, collision detection, extensibility, support for VR input/output devices, 3D libraries, widgets, development support and methods of publication of an application [24].

The simulation of the equipment in the laboratory environment of virtual reality is based mainly on the quality of the visual information and high-resolution digital images, as a way of immersion that enhances the feeling of being truly in the physical space of the laboratory itself.

This virtual lab can not only improve the accessibility, but also allows students to interact with $3 \mathrm{D}$ equipment models, using a rich multimedia contents in which they can learn the technical meaning of assemblies and associated information, within a 3D environment [22].

Students can also use this virtual lab to learn about the meaning of certain type of laboratory equipment and associated information. Browsing and the use of various media are important design elements to increase the usability of a 3D virtual lab environments, with an emphasis on the informative aspect and the learning context. Fig. 1 shows the home page of VEMA.

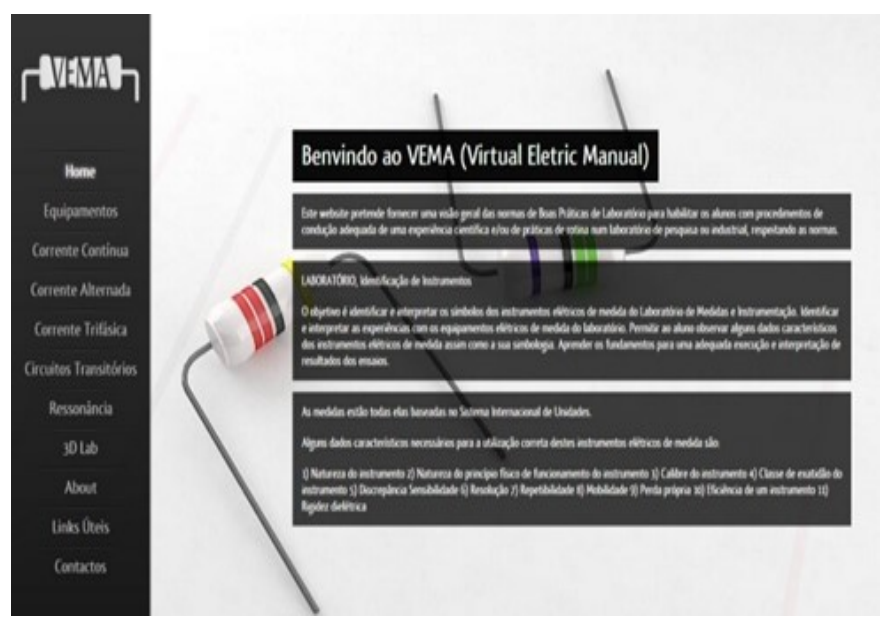

Fig. 1 Home page of VEMA.

Fig. 2 shows the Equipment menu page of VEMA.

Users can view basic information about the fundamentals of electrical engineering: curriculum, assessment criteria, schedule of laboratory exercises and homework. There is also a menu list with the teacher's contact. All visitors can view interactive learning materials and links on electrical engineering [24].
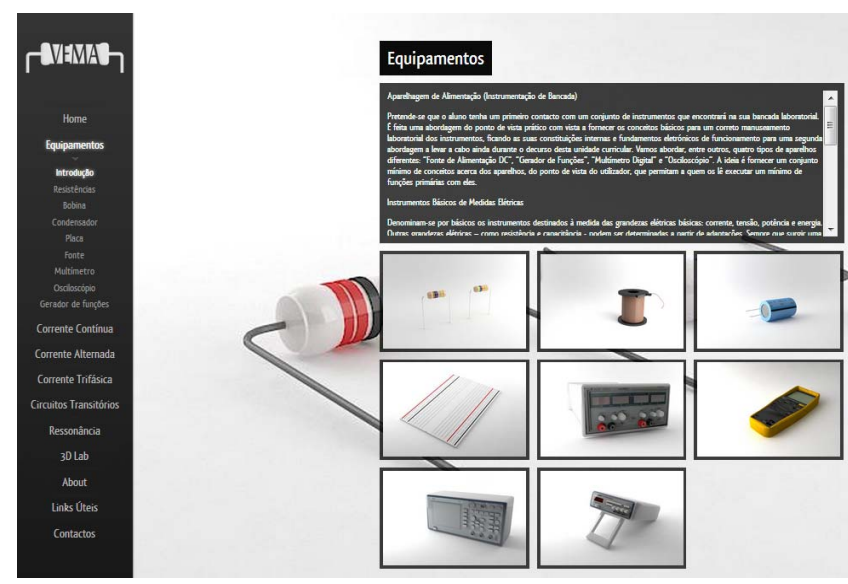

Fig.2 System User Interface - Equipment menu page

\section{CONCLUSION}

This is a project developed by DEE/ISEC which seeks to give students access to e-learning tools through the use of 3D Virtual Worlds providing an interface for interacting with e-learning, that is, a 3D interface is used instead of a $2 \mathrm{D}$ browser [20].

There is interoperability between the e-learning system and the virtual 3D environment to ensure that different platforms can perform the same actions in the LCMS, regardless of the interface.

The purpose of the $3 \mathrm{D}$ prototype was to experimentally validate the theoretical model as a design tool for creating 
virtual 3D environments that improve access to laboratories as resources of information and learning. The prototypes must be built as close to the final product as possible, in order to evaluate how students respond to the final products. Therefore, the $3 \mathrm{D}$ prototype was created as realistically as possible to resemble the final product of the work so that the students can identify if the use and pedagogical approaches correspond to what was foreseeable.

The prototype was created based on the design and analysis of a model using several software programs, namely, $3 \mathrm{ds}$ Max, VizUp, Dreamweaver, Wirefusion and HTML5. The virtual prototype design aimed at attracting and engaging students in the $3 \mathrm{D}$ virtual environment.

This program allows students to learn through their own exploration and research of selected virtual objects using a variety of interactive learning activities. It is active learning by discovery, as opposed to merely passive learning.

\section{REFERENCES}

1] Cosmin Porumb, Bogdan Orza, Dan D. Micu, Sanda Porumb, Cloud Computing and its application to blended learning in engineering, 8th International Conference eLearning and Software for Education, eLSE 2012, Bucharest, Aprilie 26-27, pp. 253-258, 2012.

[2] Cosmin Porumb, Sanda Porumb, Dan D. Micu, Bogdan Orza Collaborative Learning Concept for Lifelong Learning, 8th International Conference eLearning and Software for Education, eLSE 2012, Bucharest, Aprilie 26-27, pp. 518-524, 2012.

[3] Ghislandi, P. and Job, R., Collaborative learning for an online higher education course: a case study. 2005. Proceedings of the ICALT, IEEE International Conference on Advanced Learning Technologies, pp. 245 246, 2005.G. Eason, B. Noble, and I.N. Sneddon, "On certain integrals of Lipschitz-Hankel type involving products of Bessel functions," Phil. Trans. Roy. Soc. London, vol. A247, pp. 529-551, April 1955.

[4] B. Z. Perez, M. M. Marin and E. I. Perez, Developing a Virtual Environment for Safety Training, in Electronics, Robotics and Automotive Mechanics Conference, Morelos, pp. 545 - 550, 2007.

[5] Yang Wang, Lifeng Wang, Zewei Zheng, Application of Virtual Prototype Technology to Simulation Test for Airborne Software System, Advances in Electronic Engineering, Communication and Management vol.2, pp. 653-658, 2012.

[6] Stephen C. W. Kong, A Framework for Implementing Virtual Prototyping in Construction, 2nd International Conference on Emerging Trends in Computer and Image Processing (ICETCIP'2012) June 30-July 1, Bali, 2012.

[7] F. M. M. Raminhos, M. M. Travassos Valdez, C. Machado Ferreira, "Impact of ICT in a Specialization Technological Course", Proceedings da ieTIC 2012 - Conferência Ibérica em Inovação na Educação com TIC, Junho $1-2,2012$.

[8] Conceição-Runlee, S. and Daley, B.J., Constructivist learning theory to web-based course design, in Proceedings of the 17th annual midwest research-to-practice conference in adult, continuing and community education, 1998.
[9] BinShyan Jong, YuLung Wu, TeYi Chan, Dynamic Grouping Strategies Based on a conceptual Graph for Cooperative Learning, IEEE Transactions on Knowledge and Data Engineering, vol. 18, no. 6, pp. 738-747, doi:10.1109/TKDE. 2006.93, June 2006.

10] G. Gabrysiak, H. Giese and A. Seibel, Towards Next Generation Design Thinking: Scenario Based Prototyping for Designing Complex Software Systems with Multiple Users, in H. Plattner, C. Meinel \& L. Leifer, Design Thinking: Understand-Improve-Apply, Springer Verlag, 2010.

[11] G. Funchal, M. Moy, F. Maraninchi, L. Maillet-Contoz, Faithfulness Considerations for Virtual Prototyping of Systems-on-Chip, Verimag Research Report no TR-2010-13, May 18, 2010.

[12] L. Chittaro and R. Ranon, Web3D technologies in learning, education and training: Motivations, issues, opportunities, Computers \& Education, vol. 49, no. 1, pp. 3-18, August 2007.

[13] E. Ai-Lim Lee, W. Wai and C. Fung, How does desktop virtual reality enhance learning outcomes? A structural equation modeling approach, Computers and Education, vol. 55 (4). pp. 1424-1442, June 2010.

[14] D.W. Johnson and R.T. Johnson, Learning Together and Alone: Cooperative, Competitive, and Individualistic Learning, 5/E. N.J.: Allyn and Bacon, 1999.

[15] A. Fratu, M. Fratu, Simulation of articulated robots for virtual prototyping in dynamic $3 \mathrm{~d}$ environments, Bulletin of the Transilvania University of Brasov, Series I: Eng. Sciences, vol.5(54), No. 1, 2012.

[16] T. Huang, C. W. Kong, H. L. Guo, A. Baldwin, Heng Li, A virtual prototyping system for simulating construction processes, Automation in Construction 16, 576-585, 2007.

[17] S.H. Choi and H.H. Cheung, A versatile virtual prototyping system for rapid product development, Computers in Industry, vol. 59, Issue 5, pp. 477-488, May 2008.

[18] Rudolf Volner, Engineering Environment and Avionics Virtual Prototyping, Electronic technical journal, Number 2, vol. VII, July 2012.

[19] S.H. Choi and H.H. Cheung, A multi-material virtual prototyping system, Computer-Aided Design 37 (1) 123-136, 2005.

[20] M. Travassos Valdez, C. Machado Ferreira and F. P. Maciel Barbosa, "Distance Education Using a Desktop Virtual Reality (VR) System", 24th EAEEIE Annual Conference, EAEEIE2013 (European Association for Education in Electrical and Information Engineering), Chania, Crete, Greece, May 30 - 31, 2013.

[21] M. M. Travassos Valdez, C. M. Machado Ferreira e F. P. Maciel Barbosa, "Cooperative Distance Learning to Electrical Engineering Education using Virtual Laboratories", EAEEIE2012, 23rd EAEEIE Annual Conference, Cagliari, Italy from 26th - 27th February 2012. EAEIEE (European Association for Education in Electrical and Information Engineering).

22] M. Travassos Valdez, C. Machado Ferreira and F. P. Maciel Barbosa "Virtual Reality Prototype as a tool in a lab environment", Chapter book Wroclaw, "Project Work and Internship - Theory and Practice", ISBN: 978-83-63987-00-8, e-Book ISBN: 978-83-63987-01-5, Praxis 2011.

[23] M. Travassos Valdez, C. Machado Ferreira and F. P. Maciel Barbosa, "Software Packages to Support Electrical Engineering Virtual Lab", International Journal on Emerging Technologies in Learning, iJOE2012. ISSN: 1861-2121. Vol. 8, Special Issue 2:"exp.at'11, pp.19-23, Special Focus Papers, Fevereiro 2012.

24] M. Travassos Valdez, C. Machado Ferreira and F. P. Maciel Barbosa "Desktop VR Systems - A Distance Learning Method and Technology", Special Track "IT and Engineering Pedagogy" (ITEP'13) EDUCON 2013 Conference in Berlin, IEEE Global Engineering Education Conference, March 13-15, 2013. 